\title{
Acanthosis Nigricans and Metabolic Risk Factors in Obese Children
}

\author{
Srinivasan Thiagarajan ${ }^{1} \cdot$ Thirunavukkarasu Arun Babu $^{2}$ (D) $\cdot$ Prakash Manivel $^{3}$
}

Received: 29 July 2019 / Accepted: 9 September 2019 / Published online: 16 October 2019

(C) Dr. K C Chaudhuri Foundation 2019

To the Editor: Metabolic syndrome in childhood obesity is common and leads to further complications like type 2 diabetes, hypertension, dyslipidemia etc. [1]. Acanthosis nigricans (AN) serves as an external marker for predicting metabolic syndrome and insulin resistance in adults. In obese children, western studies have proven a similar role of AN in predicting metabolic risk factors [2]. In India, however, there is paucity of data to prove this hypothesis in obese children. The prevalence of AN in obese school going children was estimated to be $26 \%$ [3]. We did a study to find out the relationship between AN with anthropometric parameters like BMI, minimal waist circumference and metabolic risk factors like fasting blood glucose, fasting lipid profile and blood pressure among obese children.

Children attending OPD, aged 5 to $15 \mathrm{y}$, with body mass index (BMI) equivalent to adults more than $23 \mathrm{~kg} / \mathrm{m}^{2}$ were included in the study. Children with adult equivalent BMI more than $27 \mathrm{~kg} / \mathrm{m}^{2}$ and less than $27 \mathrm{~kg} / \mathrm{m}^{2}$ were categorized as obese and overweight respectively, according to age and sex [4]. Neck examination was done for diagnosis and grading of AN according to Burke et al. (Grade 0 to 4) [5]. Based on the grading of AN, the study population was divided into Group 1 (Non-significant AN - Grades $0 \& 1)(n=75)$ and Group 2 (Significant AN - Grades 2, 3 and 4) $(n=90)$. There was statistically significant difference in mean BMI between Group $1\left(22.76 \mathrm{~kg} / \mathrm{m}^{2}\right)$ and Group $2\left(24.73 \mathrm{~kg} / \mathrm{m}^{2}\right)$ confirming that children with significant acanthosis had higher BMI than children with nonsignificant acanthosis $(p=0.0001)$. Systolic blood pressure and waist circumference were significantly higher in Group 2 with $p$ values of 0.014 and 0.003 respectively. Triglyceride and

Thirunavukkarasu Arun Babu babuarun@yahoo.com

1 Department of Pediatrics, Indira Gandhi Medical College and Research Institute, (IGMC\&RI), Puducherry, India

2 Department of Pediatrics, All India Institute of Medical Sciences (AIIMS), Mangalagiri 522503, India

3 Department of PSM, Indira Gandhi Medical College and Research Institute (IGMC\&RI), Puducherry, India very low density lipoprotein (VLDL) levels were higher in the Group 2 with $p$ values of 0.02 and 0.014 respectively. Logistic regression analysis showed significant association of high BMI with severity of AN ( $p$ value: 0.05 ; AOR: 1.248 ). We conclude that severity of AN is associated with higher BMI, higher waist circumference, high systolic blood pressure and high triglycerides and VLDL levels in overweight and obese children.

\section{Compliance with Ethical Standards}

Conflict of Interest None.

\section{References}

1. Weiss R, Dziura J, Burgert TS, Tamborlane WV, Taksali SE, Yeckel $\mathrm{CW}$. Obesity and the metabolic syndrome in children and adolescents. N Engl J Med. 2004;350:2362-74.

2. Palhares HMDC, Zaidan PC, Dib FCM, Silva APD, Resende DCS, Borges MF. Association between acanthosis nigricans and other cardio metabolic risk factors in children and adolescents with overweight and obesity. Rev Paul Pediatr. 2018;36:301-8.

3. Rafalson L, Eysaman J, Quattrin T. Screening obese students for acanthosis nigricans and other diabetes risk factors in the urban school-based health center. Clin Pediatr. 2011;50:747-52.

4. Khadilkar V, Khadilkar A. Growth charts: a diagnostic tool. Indian J Endocrinol Metab. 2011;15:166-71.

5. Burke JP, Hale DE, Hazuda HP, Stern MP. A quantitative scale of acanthosis nigricans. Diabetes Care. 1999;22:1655-9.

Publisher's Note Springer Nature remains neutral with regard to jurisdictional claims in published maps and institutional affiliations. 